\title{
Animal coronaviruses in the light of COVID-19
}

\author{
Katarzyna Domańska-Blicharz ${ }^{1 凶}$, Grzegorz Woźniakowski², Bogdan Konopka ${ }^{3}$, \\ Krzysztof Niemczuk ${ }^{4}$, Mirosław Welz ${ }^{3}$, Jerzy Rola ${ }^{5}$, Wojciech Socha ${ }^{5}$, \\ Anna Orłowska ${ }^{5}$, Marta Antas ${ }^{2}$, Krzysztof Śmietanka ${ }^{1}$, Beata Cuvelier-Mizak ${ }^{6}$ \\ ${ }^{1}$ Department of Poultry Diseases, ${ }^{2}$ Department of Swine Diseases, ${ }^{4}$ Director General, \\ ${ }^{5}$ Department of Virology, ${ }^{6}$ Department of Veterinary Pharmacy, \\ National Veterinary Research Institute, 24-100 Puławy, Poland \\ ${ }^{3}$ General Veterinary Inspectorate, 00-930 Warsaw, Poland \\ domanska@piwet.pulawy.pl
}

Received: July 1, 2020

Accepted: July 20, 2020

\begin{abstract}
Coronaviruses are extremely susceptible to genetic changes due to the characteristic features of the genome structure, life cycle and environmental pressure. Their remarkable variability means that they can infect many different species of animals and cause different disease symptoms. Moreover, in some situations, coronaviruses might be transmitted across species. Although they are commonly found in farm, companion and wild animals, causing clinical and sometimes serious signs resulting in significant economic losses, not all of them have been classified by the World Organization for Animal Health (OIE) as hazardous and included on the list of notifiable diseases. Currently, only three diseases caused by coronaviruses are on the OIE list of notifiable terrestrial and aquatic animal diseases. However, none of these three entails any administrative measures. The emergence of the SARS-CoV-2 infections that have caused the COVID-19 pandemic in humans has proved that the occurrence and variability of coronaviruses is highly underestimated in the animal reservoir and reminded us of the critical importance of the One Health approach. Therefore, domestic and wild animals should be intensively monitored, both to broaden our knowledge of the viruses circulating among them and to understand the mechanisms of the emergence of viruses of relevance to animal and human health.
\end{abstract}

Keywords: coronavirus, animals, COVID-19.

\section{Introduction}

Coronaviruses (CoVs) are a diverse group of pathogens capable of infecting many species of birds and mammals, including humans. They cause a variety of diseases across the spectrum of respiratory, digestive, urinary, and (in some cases) nervous system disorders. CoVs belong to the order Nidovirales, suborder Cornidovirineae, family Coronaviridae, and subfamily Orthocoronavirinae, which covers four genera: Alpha-, Beta-, Gamma- and Deltacoronavirus (72). It is generally accepted that alpha- and betacoronaviruses only infect mammalian species, while gamma- and deltacoronaviruses infect bird species, although some of them may also infect mammals (e.g. the beluga whale and pig).

Over the past 17 years, there have been three epidemics in humans caused by betacoronaviruses:
SARS (severe acute respiratory syndrome), MERS (Middle-East respiratory syndrome) and COVID-19 (coronavirus disease 2019). The SARS and COVID-19 outbreaks were caused by SARS-CoV-1 and SARSCoV-2 of the subgenus Sarbecovirus while MERS had its aetiology in CoVs from the subgenus Merbecovirus. The SARS epidemic took place in 2002-2003 and was quickly controlled, lasting only 8 months, although a total of 8,096 people were infected and the mortality rate was $9.5 \%$ (9). The MERS epidemic started in 2012 and continues to the date of writing. By December 2019, 2,468 people had been infected and MERS had a $42 \%$ mortality rate (73). An epidemic pneumonia called COVID-19 started in December 2019 in the city of Wuhan, China and soon spread all over the world. A few months later, on the $11^{\text {th }}$ of March, 2020, the disease was declared a pandemic by the World Health Organization (WHO) (11). 
CoVs are pleomorphic in structure and have one of the largest single-strand RNA genomes of about 26-32 kilobase pairs in size and a unique replication strategy (35). The most prominent feature of coronaviruses, and the feature which defines them, are the spikes on the surface of the virion, which resemble a solar corona (hence their name). All CoVs exhibit a similar genome organisation that may be succinctly described as 5'-pollab-S-E-M-N-3 '. Two thirds of the genome from the $5^{\prime}$ end encodes RNA-dependent RNA polymerase (RdRp) and the remaining third encodes four structural proteins: S (spike), E (envelope), M (membrane) and $\mathrm{N}$ (nucleocapsid). This part of the genome also encodes a few low molecular accessory proteins whose number and nature vary depending on the species and even the $\mathrm{CoV}$ strain. Some betacoronaviruses have an additional structural protein, haemagglutinin esterase (HE). Of the four (or sometimes five) structural proteins, it is S glycoprotein that plays a key role in the initial stage of $\mathrm{CoV}$ infection of host cells and induction of protective immunity. Two subunits can be distinguished in the structure of the S protein - one encoded by the S1 coding region and the other by the $\mathrm{S} 2$. The $\mathrm{S} 1$ forms the distal part of the spikes and interacts with the host receptor through the receptor binding domain (RBD), initiating the infection. The $\mathrm{S} 2$ anchors spikes in the virus envelope and mediates fusion of the virion and cellular membranes. Consequently, the spike is the most divergent among all coronavirus proteins (60). The S1 subunits are particularly divergent, with low sequence similarities across different genera (59). Depending on the species, coronaviruses use different receptors and mechanisms for cell fusion to enter host cells (35). Sarbecoviruses related to SARS-CoV-1 use the human angiotensin-converting enzyme 2 (ACE2) receptor, whereas merbecoviruses related to MERS-CoV utilise the dipeptidyl peptidase-4 (DPP4) receptor (58). Cell entry through the ACE2 receptor was also confirmed for SARS-CoV-2 (43, 129). In turn, igacoviruses in the Gammacoronavirus genus recognise different receptors depending on tissue tropism. Respiratory strains of the chicken infectious bronchitis virus (IBV) require specific alpha-2,3-linked sialylated glycans, while enteric gammacoronaviruses (turkey or guinea coronaviruses) recognise a unique set of nonsialylated type 2 poly- $N$-acetyl-lactosamines or both types of receptor for attachment and entry to avian cells, in the case of some virus strains $(13,114)$.

CoVs undergo many genetic changes generated by recombinations and mutations such as substitutions, deletions, and insertions. Additionally, they could also evolve through the gene gains and losses mechanism $(37,98)$. This mechanism was first described for human betacoronaviruses (SARS- and MERS-CoVs) and mainly concerns accessory protein genes. The gain or loss of such genes could lead to drastic changes in the viral phenotype such as adaptation to another host, the ability to avoid the immune response or changes in virulence (37). It seems that a similar mechanism is also operational in gammacoronaviruses. Genome analysis of the gammaCoV/Ck/Italy/I2022/13 strain of GI-11 genotype did not show the presence of the accessory 6b gene (69). However, a strain of the same genotype identified several years earlier called gammaCoV/Ck/Italy/IP14425/96 had this gene (52). The function of the protein encoded by this gene is still unknown.

Among factors that favour such events are characteristic features of coronaviruses in the genome structure (that it is a large single-stranded RNA), virus biology (the minimal proofreading activity of RdRp and peculiar genome organisation) and selection pressure during adaptation of the virus to the new conditions (i.e. a new host). This remarkable variability of coronaviruses means that they can infect many different animal species and cause different disease symptoms. Moreover, in some situations coronaviruses might be transmitted across species (24). Deep molecular genome analysis of human coronaviruses indicates their animal origin. Most of them originally came from bats and then were transmitted to humans through intermediate hosts. SARS-CoV-1 emerged through recombination of bat SARS-related CoVs, which then infected civets and humans and adapted to these hosts before the SARS epidemic (111).

In this aspect, it is essential to have the widest knowledge of coronaviruses circulating in animals. Explaining the ecology and diversity in animal reservoirs is important for our ability to respond to the likely future emergence of coronaviruses in economically important animal species or the human population. In this review, we summarise the impact of coronaviruses on the health of farm, companion, and some wild animals.

\section{Bat coronaviruses}

Before the SARS epidemic, bats were not known to be hosts for coronaviruses $(\mathrm{CoV})$. This situation changed after 2003, when the intensive search for novel CoVs in various mammals enabled the identification of over 500 (https://edition.cnn.com/2020/ 04/26/health/virus-hunters-bat-cave-coronavirus-hnkintl/index.html). Among the four $\mathrm{CoV}$ genera, alphaand betacoronaviruses have been found in various species of bats around the world $(8,29)$. Some SARSrelated CoVs identified in horseshoe bats in China in the post-2003 period could easily replicate in human cells (38). It even transpired that five out of the seven human CoVs (HCoVs) detected so far, i.e. alphacoronaviruses HCoVs-229E and HCoVs-NL63 and SARS-CoV, MERS-CoV and SARS-CoV-2 were transmitted to humans from bats by intermediate hosts, including alpacas, wild carnivores, dromedary camels and, supposedly, pangolins (28). Phylogenetic and evolutionary analysis of the broad range of Chinese bat CoVs using Bayesian approaches revealed frequent cross-species transmission events occurring among bats that increased the risk of the emergence of new CoVs. 
The rate of occurrence of inter-family host-switching events was, however, five times higher in the evolutionary history of alpha- than that of beta-CoVs in China. Moreover, phylogenetic reconstructions for alpha- and beta-CoVs suggested an evolutionary origin of viruses in rinolophid and vespertilionid bats (53). Rhinolophus spp. bats were the hosts of swine acute diarrhoea syndrome coronaviruses (SADS-CoVs) that caused the death of over 25,000 pigs on one farm in Guangdong province, China in 2016 (128). The recently discovered SARS-CoV-2 also revealed its closest relationship to be to viruses sampled from the Malayan horseshoe bat (Rhinolophus malayanus), the intermediate horseshoe bat ( $R$. affinis) and Malayan pangolins (Manis javanica). Its full genome similarity to a viral sequence reported in $R$. affinis (BatCoVRaTG13) collected from Yunnan province and to other SARSrelated CoVs identified from pangolins was 96.2\% (100, 129). Although BatCoVRaTG13 is the closest to SARSCoV-2 across the full genome, some pangolin coronaviruses exhibit strong similarity to SARS-CoV-2 in the RBD of the $\mathrm{S} 1$ coding region (4). All known SARS-CoV-2 genomes have similar genomic features and are thus derived from a common ancestor (probably coronaviruses of bats). However, there is no clear data from which to know if SARS-CoV-2 needed an intermediate host before being able to infect humans, as was the case for SARS-CoV-1 and other HCoVs. Evolutionary study revealed that SARS-CoV-2 has required no significant adaptation to humans since the pandemic began, no selective sweep having been observed to date. Significant evidence of positive episodic selection has been established, and so it may be inferred that SARS-CoV-2 was able to transmit from human to human before it jumped from bats to humans (67).

\section{Pig coronaviruses}

Coronaviruses occurring in pigs belong to six different species comprising porcine epidemic diarrhoea virus (PEDV), transmissible gastroenteritis virus (TGEV), porcine respiratory coronavirus (PRCV), SADS-CoV, porcine haemagglutinating encephalomyelitis virus (PHEV) and porcine deltacoronavirus (PDCoV). Four of them, namely PEDV, TGEV, PRCV and SADS-CoV belong to the Alphacoronavirus genus, while PHEV belongs to Betacoronavirus and PDCoV to Deltacoronavirus (89, 110, 127). Regarding the economic impact on production, infections caused by PEDV are the most significant due to its high infectivity and the high mortality of the disease it causes, especially among groups of suckling piglets, where it may reach $100 \%$. The disease may also occur in all life-stage groups of pigs, including sows and fatteners. PED is less harmful to older pigs where the prevalence is approximately $20 \%$. Clinical signs of PED are manifested as watery diarrhoea, vomiting and apathy (17, 75). PED was first described in 1977 in Belgium, then almost simultaneously between 2013 and 2015 the disease was found in all US States, and then in Germany, where the presence of specific antibodies in pigs was found on every fifth farm examined. PED was also diagnosed in France, Bulgaria, Italy, Hungary, the Czech Republic, the Netherlands and Switzerland $(19,65,79)$. In Poland, no cases of PED have been confirmed so far. However, in the course of many diseases of the digestive tract of pigs where diarrhoea is observed, the possibility of PEDV infection is also taken into account during differential diagnosis. There is only one PEDV serotype, whose strains can be classified into 2 genetic groups. These are the G1 group, called the European strains (e.g. CV777), which are classic strains with moderate pathogenicity, and the G2 group of American and Asian strains with high pathogenicity. Within the groups a certain variety can be distinguished, hence subgroups of strains have been described, namely G1a and G1b and $\mathrm{G} 2 \mathrm{a}$ and $\mathrm{G} 2 \mathrm{~b}$. In addition, the strains belonging to PEDV group $\mathrm{G} 2$ which have a deletion or insertion in the $\mathrm{S}$ gene were classified as S-INDEL variants from the originally isolated CV777 strain $(87,96,97)$. The virus may spread with traded pigs that are asymptomatically infected and shed the virus into the environment with faeces. The pigs become infected by ingestion after taking faeces-contaminated feed. The virus reaches the small intestine through the stomach, replicating most efficiently in the jejunum and iliac enterocytes. Approximately 36 hours after infection, the virus destroys the intestinal villi, which are significantly shortened, resulting in impaired absorption in the digestive tract, electrolyte imbalance and clinical signs such as watery diarrhoea with a green or pale yellow colour. During the post mortem examinations of piglets with PED, hyperaemia and distension of the small intestine and undigested milk clots may be observed. The most important objective in PED diagnosis is to distinguish the disease from TGE, which has almost identical clinical symptoms and lesions (17, 19). Fragments of the small intestines or faecal samples should be collected for laboratory diagnosis. In serological diagnosis, blood should be collected without anticoagulant. Currently, tests for PED serological diagnosis by the ELISA method and molecular diagnosis by the PCR method are widely accessible. The most important issue in PED prophylaxis is the implementation of the proper biosecurity rules to prevent the spread of the disease onto the farm. Attenuated, subunit and inactivated vaccines against PED are used in the United States of America and Asia. Other studies on recombinant vaccines including DNA vaccines are ongoing. The $P E D$ vaccines are available as bi- or trivalent solutions to immunise sows against PED, TGE and E. coli. A feedback-type strategy may be also applied, where the homogenate of the guts of piglets that have died of PED is given to pregnant sows 2-3 weeks before farrowing, which prevents infection and reduces mortality among piglets $(49,70)$.

Another representative of porcine coronaviruses is TGEV. Transmissible gastroenteritis was described for 
the first time in 1946 in the United States. Since then, the disease has also been reported in other countries where pig production is on a large scale, including Belgium, England, France, Germany, the Netherlands and Spain in Europe, Japan, Korea, Malaysia and Taiwan in Asia, the countries of North, Central and South America, and Zaïre and Ghana in Africa (56, 81, 82 ). The losses caused by TGE are similar to those imposed by PED; however, infection usually occurs during farrowing. As in the case of PED, the course of the disease is acute or subacute, and the virus spreads with the faeces of infected pigs. In the subacute form, the disease can be confused with diarrhoea caused by E. coli, rotavirus, or PEDV infection, and therefore laboratory diagnosis is important for final identification. The subacute form of TGE may be asymptomatic in adult pigs. A history of infection of pigs with porcine respiratory coronavirus may lead to cross protection against TGEV infection, given that $\mathrm{PRCV}$ is a deletion variant of TGEV $(81,89)$. Similarly to PEDV, TGEV infects small intestine enterocytes, leading to the destruction of intestinal villi and reduction of the intestinal absorption. TGE may occur in all age groups of pigs and causes almost $100 \%$ mortality among suckling piglets. Among older piglets over 4 weeks of age, the mortality rate is significantly lower at $50-70 \%$, with the lowest rate of $20 \%$ being among adult pigs. The TGE incubation period is shorter than in PED and ranges from 24 to 36 hours. Similarly to cases of PED, TGE cases cause piglets to die because of nutrient malabsorption and dehydration due to the destruction of the small intestine. The main clinical sign of TGE is greyish or green diarrhoea and vomiting $(5,49)$, and the lesions are similar to those observed in PED infection. There is only one TGEV serotype which occurs in herds that have not previously been exposed to PRCV. A previous TGEV infection causes local intestinal immunity associated with secretory $\operatorname{IgA}$ antibodies that may last for a few months to several years. Laboratory diagnosis of TGE is performed by serological assays in order to identify specific antibodies as well as by PCR in order to distinguish TGEV from $\operatorname{PRCV}(5,92,112)$. The small intestine and faeces are collected for laboratory testing; however, the period of virus shedding is restricted to 7 days after infection. The feedback strategy used in PED prophylaxis is also used to prevent infection by TGEV.

The characterisation of complete PRCV genomes showed a large deletion (621-681 nt) close to the $\mathrm{N}$-terminus of the $\mathrm{S}$ gene, which leads to translation of a truncated S-protein form. PRCV also has a variable region with deletions within ORF3, which is located downstream from the $\mathrm{S}$ gene, and variations here may abrogate the tropism of this virus to the host cells. Therefore, the overall identity of genomic sequences (near 98\%) between TGEV and PRCV suggest their common origin. The shedding of PRCV with faeces is limited, and there is no evidence of PRCV transmission with saliva. PRCV epidemiology might be directly related to pig population density and the distance between farms, where distance is a factor because the virus can be transmitted by the airborne route over a distance of several kilometers. PRCV may infect also pigs by contact and no age groups are insusceptible. Experiments showed that the susceptible pigs experimentally infected with PRCV shed virus from nasal secretions for less than 2 weeks. PRCV can persist in the herd throughout the whole year, or incidentally disappear from the infected herd during summer and then reappear in sows or fattening pigs during the winter season.

Another pig disease caused by a coronavirus is haemagglutinating encephalomyelitis (HE) caused by the haemagglutinating encephalomyelitis virus (HEV) (66). HE was diagnosed for the first time in Western Europe and the USA in the 1970s. The virus was also identified in Western Poland on commercial farms. Currently, this disease is not recorded. HE occurs in suckling piglets without any clinical signs, but the course of the disease manifests central nervous system signs one week after infection when the virus replicates in the stomach and ganglia. The initial symptom is vomiting and there is an undigested milk clot in the stomach. A less frequent clinical sign is a lack of locomotor coordination in infected pigs. HE can be detected in about $80 \%$ of piglets. Sows that have been infected with HEV pass specific antibodies to piglets with colostrum, which protects them until 4 weeks of age. The only method of HE prophylaxis is early contact of piglets with sows $(62,66)$.

In 2016, the new pig coronavirus SADS-CoV occurred in China. It caused high mortality among suckling piglets. Then, another new recombinant strain of swine enteric coronavirus ( $\mathrm{SeCoV}$ ) was confirmed in Italy, Germany, the Czech Republic and Slovakia (68, 127).

Porcine deltacoronavirus (PDCoV) was first described in 2007 in China and then in 2012 in Hong Kong. In addition, between 2005 and 2006 the presence of deltacoronaviruses was confirmed sporadically in China among other free-ranging species of animals, including badgers and leopards. The origin of PDCoV in pigs remains unclear and the virus shows incomplete adaptation to pigs $(49,56)$. Unfortunately, in 2014 PDCoV was identified in 19 US states among suckling piglets. That year PDCoV was also identified in Canada, South Korea, Mexico, Thailand and Vietnam. Until now, the surveillance studies conducted in Poland showed no presence of PDCoV in pigs. The economic losses caused by PDCoV are difficult to estimate, but might be lower than those caused by the spread of PED or TGE (110). In terms of the molecular structure, $\mathrm{PDCoV}$ is highly similar to other members of this family, but many of the individual functions of this virus' replication are still unknown (49). Common clinical signs of PDCoV infection are diarrhoea, dehydration and less frequently vomiting. In comparison to PED and TGE, the clinical signs caused by deltacoronavirus are milder while the mortality rates reach 40 to $80 \%$ in suckling piglets. In older pigs the 
infection can be asymptomatic. Similarly to PEDV and TGEV, PDCoV also infects and damages porcine small intestine enterocytes and colon cells $(7,49,110)$. In laboratory diagnosis serological ELISA and PCR tests might be applied. Due to the lack of PDCoV vaccine, the only preventive measure is to maintain effective biosecurity rules, and in case of infection, established practice is to provide symptomatic treatment and protection of piglets against dehydration and secondary infection with pathogenic bacteria including Actinobacillus pleuropneumoniae or Mycoplasma hyopneumoniae (110).

\section{Bovine coronavirus}

Bovine coronavirus $(\mathrm{BCoV})$ is a causative agent of neonatal calf diarrhoea, winter dysentery in adult dairy cattle and respiratory tract infections in cattle of all age groups $(30,91)$. As a pneumoenteric virus, it is frequently isolated from both faecal samples of calves with diarrhoea and samples from cattle with respiratory symptoms. In the past it was speculated that various clinical forms of $\mathrm{BCoV}$ infections are caused by different strains of the virus characterised by a distinct genotype (39). However, a recent study does not support this finding, rather associating different types of disease with environmental and host factors (99). According to the current guidelines of the International Committee on Taxonomy of Viruses, $\mathrm{BCoV}$ is a member of the subgenus Embecovirus in the genus Betacoronavirus of the family Coronaviridae (talk.ictvonline.org/taxonomy). $\mathrm{BCoV}$, together with coronaviruses infecting other ruminants (such as sheep, goat, water buffalo and llama) as well as one of the human coronaviruses, $\mathrm{HCoV}$ OC43, belongs to the species Betacoronavirus 1 (28). This wide range of host species of Betacoronavirus 1, unusual in comparison with other coronavirus species, has not been fully explained yet (23). There are certain indicators that $\mathrm{BCoV}$ and related viruses have zoonotic potential and therefore could become a threat to human health. In vitro studies showed that due to the high variety of quasispecies population, $\mathrm{BCoV}$ could easily adapt to and infect various human cell lines through the selection of variants possessing specific changes in the Spike (S) protein (12). High nucleotide identity of $96 \%$ between $\mathrm{BCoV}$ and $\mathrm{HCoV}$ OC43 suggests that a similar process took place in natural conditions in the past. Genetic comparison and molecular clock analysis showed that the appearance of $\mathrm{HCoV}-\mathrm{OC} 43$ was the result of zoonotic transmission from bovines to humans that took place in around the 1890s (51). The mooted mechanism that led to this event was a 290 long nucleotide deletion downstream of the spike gene, which enabled $\mathrm{BCoV}$ to adapt to the human host $(23,109)$. However, as the report of the isolation of a BCoV-related virus in a 6-year-old child with diarrhoea (125) showed, interspecies transmission to humans could appear even without radical changes in the genetic structure of the viral genome.
Although similarly to SARS-CoV-2, BCoV belongs to the genus Betacoronavirus, due to the high variability among coronaviruses, the structure and sequences of its genomes are highly divergent. The first important genetic difference in $\mathrm{BCoV}$ is that similarly to most viruses of the subgenus Embecovirus, apart from the standard set of genes typical of most coronaviruses, it possesses an additional haemagglutinin-esterase (HE) gene not present in other viruses from the genus Betacoronavirus including SARS-CoV-2. HE protein is believed to be the second viral attachment protein in addition to $\mathrm{S}$ protein (50) and may be one of the factors responsible for the wide host range of Betacoronavirus 1(88). The presence of the HE gene in Embecovirus is presumably the result of relatively recent recombination with influenza $\mathrm{C}$ virus by the common ancestor of all viruses from that subgenus (121). Comparative analysis of the full amino-acid sequence of spike and nucleocapsid proteins of $\mathrm{BCoV}$ and SARSCoV-2 showed only $38.4 \%$ and $38.9 \%$ identity, respectively. However, comparison of major antigenic epitopes of those proteins showed significant similarities between them. Therefore it was speculated that prior contact with $\mathrm{BCoV}$ could provide some beneficial effect in case of later infection with SARS-CoV-2 or on the contrary, in case of recurring exposure a more violent immune response could be triggered, leading to severe clinical symptoms and a much less favourable clinical outlook $(103,104)$.

\section{Equine coronavirus}

Equine coronavirus (ECoV) is a pathogen of horses and donkeys transmitted via the faecal-oral route. The virus usually causes mild infections, with the dominant symptoms being anorexia and pyrexia. Gastrointestinal and neurological signs appear rarely in only around $10 \%$ and $3 \%$ of infected horses, respectively. ECoV belongs to the species Betacoronavirus 1 of the subgenus Embecovirus of the genus Betacoronavirus $(28,86)$ and is closely related to $\mathrm{BCoV}$ with over $90 \%$ genetic similarity (122). As ECoV was isolated for the first time only recently, and since that time infections with this virus have been detected only sporadically, little is known about the epidemiology and evolution of this virus (86). However, based on molecular clock analysis it was estimated that this virus diverged from $\mathrm{BCoV}$ at the end of 18th century, 100 years earlier than $\mathrm{HCoV}$ OC43. This suggests that it has been present in the horse population long before the first isolation in 1999 (10).

\section{Feline and canine coronaviruses}

Feline and canine coronaviruses are classified in the genus Alphacoronavirus, with the exception of canine respiratory coronavirus belonging to the genus Betacoronavirus (57) of the family Coronaviridae 
$(2,26,95)$. Feline coronaviruses (FCoVs) are usually responsible for mild infections of the intestinal tract but they may also cause an immune-mediated fatal disease feline infectious peritonitis (FIP) (25). FCoV comprises two biotypes: the feline infectious peritonitis viruses (FIPV) and the feline enteric coronaviruses (eFCoV). On the basis of in vitro neutralisation with the use of monoclonal antibodies, two serotypes of FCoV (I and II) have been identified. Each serotype includes viruses of both the FIPV and eFCoV biotypes $(44,45)$. The type II FCoV probably originated as a result of RNA recombination when the spike gene of canine coronavirus was incorporated into the FCoV type I genome. A higher prevalence of eFCoV than FIPV is demonstrated and $70-85 \%$ of FIP cases are due to infection with type I viruses $(42,76)$. Their in vitro growth characteristics distinguish type I and II viruses from each other. It is known that serotype I members rarely propagate in cell cultures. The biotype eFCoV usually causes mild enteritis, and very often natural as well as experimental infections are subclinical. Prevalence of FIP in the cat population is connected with the mutation rate of eFCoV to FIPV (108) which is responsible for a fatal disease of cats indicated by anorexia, chronic fever, and malaise. Neurological or ocular symptoms may also occur. Having worldwide distribution, FIP is the major cause of death among young domestic cats originating mainly from purebred lines and among wild Felidae $(36,80)$.

There are three different coronaviruses which have been described in dogs $(34,83)$. Canine coronavirus (CCoV) type I and type II are members of the group 1 coronaviruses. It is known that their evolution is related to the evolution of feline coronavirus (FCoV) type I and type II. FCoV type II originated as a result of heterologous recombination between $\mathrm{CCoV}$ type II and FCoV type I. CCoV type I is genetically more similar to FCoV type I than to CCoV type II (83). Infection in dogs caused by coronaviruses of group 1 is usually selflimiting and produces only mild or asymptomatic forms of enteritis (102). Canine respiratory coronavirus $(\mathrm{CRCoV})$ belongs to the group 2 coronaviruses that are not related to the group 1 enteric coronaviruses, and it actually is genetically related to the bovine coronavirus and the human coronavirus $(33,34)$. CRCoV was described for the first time in 2003 in the United Kingdom in dogs with acute respiratory infection (34). Infection with this virus was also detected in dog populations in Ireland, Greece, Italy, Japan, the U.S. and Canada, where high seroprevalence was detected - about $50 \%$ of tested dogs had antibodies to $\operatorname{CRCoV}(31,32$, $84,85,120)$. In 2006, Buonavoglia et al. (15) identified a pantropic, highly pathogenic variant of CCoV type II. The virus was isolated from internal organs of dogs with severe lesions.

In December 2019, when the first cases of SARSCoV-2 were reported in humans in Wuhan heralding the spread of the disease all over the world, the urgent question arose of whether this pantropic virus could be transmitted to animal species, and if animal species may be further reservoirs of infection. Martina et al. (71) published study results in 2003 indicating that ferrets (Mustela furo) and domestic cats (Felis domesticus) are susceptible to infection by SARS-CoV-1. Moreover these animals can transmit the virus to other cats and ferrets staying in close contact with them. These preliminary studies confirming that two distantly related carnivores can be infected with the virus indicated that a range of animal species may be a reservoir of the virus. Further studies with the use of both virological and serological methods demonstrated that Chinese ferret badgers (Melogale moschata) and masked palm civets (Paguma lavata) can also be infected with a virus very similar to SARS-CoV-1. Data from as early as 2002 concerning more than 100 people living in the Amoy Gardens blocks in Hong Kong with clinical symptoms of SARS and cats as their pets indicated that some animals were infected with SARS-CoV-1. In February 2020 the Agriculture, Fisheries and Conservation Department (AFCD) of Hong Kong issued information that a 17-year-old dog had had positive results when tested for SARS-CoV-2. Weak positive results were obtained by PCR with samples collected from oral and nasal cavities five times during a two-week period. However, the culture and the results of serological testing were negative. These findings were also confirmed by the observation and testing of another PCR-positive dog (3). It could be concluded from the obtained results that the dogs were not contagious to other dogs or people.

Reports from the United States Department of Agriculture on transmission of SARS CoV-2 from humans to domestic cats and to tigers and lions at the Bronx Zoo (106) and the results of the studies of Halfmann et al. (40) demonstrated the ease of transmission of the virus among domestic cats. Moreover, they concluded that cats not showing visible symptoms of the infection may be the silent intermediate host of SARS-CoV-2.

There are not many studies confirming the role of domestic animals in the COVID-19 pandemic, but analysis done by Shi et al. (94) clearly demonstrated that ferrets, cats and dogs can be infected in experimental conditions by the intranasal route. The possible role of the viral ACE2 receptor in this process is indicated. The dogs and ferrets in this experiment were less affected; however, the cats were more susceptible to SARS-CoV-2 infection, particularly during their juvenile post-weaning life - one out of three kept in close contact with infected cats became infected. Although these studies were performed on a limited number of cats, their results confirmed that intra-species respiratory droplet transmission can occur. It should be underlined that the dose of the virus used for the experimental infection was much higher than in natural infection and the virus was administered via the intranasal route. The serological studies of 120 cats conducted in the first quarter of 2020 in Wuhan revealed that $14.7 \%$ of animals had antibodies specific to SARS-CoV-2 (124). 
Despite the confirmed susceptibility of cats to experimental infection with SARS-CoV-2 and their indication as a potential model of SARS-CoV-2 replication, the results of the studies of Temmam et al. (101) revealed a nil or very low SARS-CoV-2 infection rate in dogs and cats, even in repeated contacts and close proximity to humans with confirmed infection. The studies were conducted in a veterinary community of 20 students in which 2 tested positive for SARS-CoV-2 and several others consecutively showed clinical signs compatible with COVID-19, and the studies also investigated 21 cats and dogs living in close contact with people. Regardless of the clinical symptoms suggestive of infection with coronavirus demonstrated by a few animals, the results of RT-PCR and serological investigation by immunoprecipitation assay were negative, confirming the hypothesis that the rate of SARS-CoV-2 transmission between humans and pets in natural conditions is extremely low.

The previous studies on canine respiratory coronavirus have demonstrated high viral titres found in the aerosols of respiratory secretions of infected dogs and resulting in a high transmission via direct contact between infected animals (15). To verify the hypothesis of interspecies transmission of the betacoronaviruses (61), Tilocca et al. (103) published the sequence homology analysis of the amino acid sequence of the spike protein from SARS-CoV-2 in comparison with some taxonomically related coronaviruses having tropism to other animal species. As a result, it was demonstrated that the resemblance of the whole sequence between SARS-CoV-2 and canine respiratory coronavirus is $36.39 \%$, but high similarity was observed in the epitope sequences of the circulating SARS-CoV2 and CoV-4 epitope sequences of canine respiratory coronavirus. Promising results were obtained by $\mathrm{Lu}$ et al. (64) demonstrating the cross reactivity of nucleocapsid $\mathrm{CRCoV}$ protein expressed in E. coli with antisera against human coronaviruses.

\section{Coronaviruses in Aves}

In Aves, coronaviruses were identified belonging to two genera, Gammacoronavirus and Deltacoronavirus. The viruses of both genera are very diverse, and research conducted all over the world is providing new evidence for this diversity. This is reflected in the taxonomy (based on the RdRp genetic features) that must be updated for these newly discovered coronaviruses. The deltacoronaviruses comprise seven species, including six avian and one porcine pathogen, but similar viruses have also been identified in Asian carnivores. According to the new taxonomy made public in March 2020, the genus Deltacoronavirus contains three subgenera, Andecovirus, Buldecovirus and Herdecovirus, instead of the previous four (the only representative of the former Moordecovirus subgenera, common moorhen coronavirus HKU21, was moved to Buldecovirus). However, the highest number of changes appeared in the genus Gammacoronavirus. Where there were formerly two, gammacoronaviruses currently comprise five species, including four of birds and one of marine mammals. Avian coronavirus (AvCoV) is in the subgenus Igacovirus and includes IBV and genetically similar viruses isolated from other domesticated galliformes. The new taxonomy has added two additional Igacovirus species, avian coronavirus 9203 and duck coronavirus 2714. In addition, a new third subgenus of gammacoronaviruses, Brangacovirus, has appeared with goose coronavirus CB17 as the main representative species. The only mammalian gammacoronavirus is SW1 in beluga whales, which was assigned to the separate subgenus Cegacovirus (https://talk.ictvonline.org/taxonomy).

The first coronavirus detected in the world was IBV and this happened in 1931 in the USA (93). Over the 89 years of research on IBV since then, it has emerged that the virus constitutes a serologically and genetically very heterogeneous group of strains, which are classified into genotypes and lineages depending on the structure of the S1 coding region (107). Currently, there are at least 7 genotypes (GI-GVII), further divided into 34 lineages, with the first IBV defined as GI-1 (Mass-like strains). Some of these genotypes are spread around the world, while some circulate locally (27). The disease caused by them, infectious bronchitis (IB), relates to the respiratory system as the name implies, but some strains can also damage the kidneys and reproductive and digestive systems. Economic losses caused by IBV were so severe that as early as in the 1950 s, the first vaccination with live attenuated strains was introduced $(21,47)$. Currently in Poland, 23 live and 13 inactivated vaccines are registered and they are the basic tool for IB control apart from strict biosecurity. Unfortunately, their effectiveness still raises many questions. According to data from the World Atlas of Animal Diseases published in November 2011 by the OIE, it appears that in 20062009 , the largest losses in the poultry industry were caused by the top 10 poultry diseases, including IB which was in second place, between highly and low pathogenic forms of avian influenza (6). It seems that the main reason for this situation is the previously described high variability typifying the Coronaviridae family and the constant emergence of new virus variants. Igacoviral avian coronavirus species in addition to IBV are those specific to turkeys (TCoV) and guinea fowls (GfCoV), both responsible for enteritis (46, 63). Avian coronaviruses in the subgenus Igacovirus have similar genomic structure and a close genetic relationship, seen in the over $86 \%$ nucleotide similarity of whole genomes between $\mathrm{TCoV} / \mathrm{GfCoV}$ and IBV strains. The most different parts of their genomes are the $\mathrm{S}$ genes, which share at most $36 \%$ identity $(14,48)$. Deep molecular analysis suggests that $\mathrm{TCoV} / \mathrm{GfCoV}$ might have emerged from recombination events between IBV and another unknown coronavirus, the donor of the $\mathrm{S}$ gene (14). The different $\mathrm{S}$ genes affected the tropism of the virus, as acquiring such a structure caused an affinity switch from the respiratory/renal system observed in the 
case of IBV to the digestive system in the case of TCoV/GfCoV $(13,114)$. The next two species of the subgenus Igacovirus are the least known. Avian coronavirus 9203 includes wild bird gammacoronaviruses similar to AvCoV/Anas crecca/Finland/9203/2010 (41). In turn, avian coronavirus 2714 contains gammacoronaviruses with a genome similar to AvCoV/duck/China/27/2014 identified for the first time in domestic ducks (130).

Viruses of the genus Deltacoronavirus were first identified in 2009 in Asian Passeriformes species (117). In the following years, there were many reports of the presence of deltacoronaviruses in wild birds in Sweden, Finland, the USA, Asia (Hong Kong and Cambodia) and Australia $(20,77,116)$. Most of these studies tested samples that were originally collected for avian influenza virus surveillance, i.e. mainly from Anseriformes and Charadriiformes. However, it seems that more deltacoronavirus species would be detected when sampling birds outside these orders, as was evidenced by recent deltacoronavirus detection in penguins on the Antarctic Peninsula (115).

Due to wild birds' possible habitats being in close proximity to humans and poultry farms, they can play an important role in spreading coronaviruses to poultry populations, and also constitute a potential source of variability of these viruses, leading to the emergence of new variants (78). Although no cross-species transmission of gammacoronaviruses has been reported so far, this has been the case for deltacoronaviruses with the emergence of porcine deltacoronavirus (123).

\section{Coronaviruses of other animal species}

Coronavirus could be an agent with two different pathological forms in rabbits: an enteric disease and a more systemic one known as myocarditis. The enteric disease shows the lesions and symptoms typical of enteritis caused by coronavirus in other species. The pathogen is transmitted via the faecal-oral route and replicates in the small intestine, bringing necrosis of the apical villi followed by diarrhoea. The most sensitive to infection are young rabbits of 3-8 weeks old, but sometimes the infection can be asymptomatic. Enteric rabbit $\mathrm{CoV}$ belongs to the species Betacoronavirus 1 of the subgenus Embecovirus in the genus Betacoronavirus (16). Recombination was possible during the evolution of this coronavirus, which might be responsible for cross-species transmission. Molecular clock analysis using RNA-dependent RNA polymerase ( $\mathrm{RdRp})$ genes dated the most recent common ancestor to around 2002, suggesting that this virus has emerged relatively recently (55). The second rabbit $\mathrm{CoV}$ which causes myocarditis was detected by electron microscopy and found to cross-react with alphacoronaviruses in serological assays. Although no gene sequence for this virus is available, the existing data suggest that it is an alphacoronavirus $(1,55)$. Recent studies demonstrated the circulation of various beta- and alpha-CoVs also in wild rabbits (74).
Similarly to bats, rodents and shrews appear to be special hosts of coronaviruses. Several species belonging to alpha- and betacoronaviruses have been identified in these orders of mammals $(54,105,113)$. The longest-known is murine $\mathrm{CoV}$ (MCoV) (subgenus Embecovirus, genus Betacoronavirus), which was first isolated at the end of the 1940s. MCoV can infect the liver, gastrointestinal tract, and central nervous system of mice, causing a wide range of diseases including hepatitis, gastroenteritis, and acute and chronic encephalomyelitis (18). Some MCoV variants also infect rats, causing respiratory symptoms (28). The next separate species of rodent coronavirus is China Rattus coronavirus HKU24, also within the Embecovirus subgenus. This virus, discovered in 2015, possesses a genome that resembles those of both Betacoronavirus- 1 and $\mathrm{MCoV}$ and probably is the murine origin of Betacoronavirus-1, with interspecies transmission from rodents to other mammals having occurred centuries ago (54). Intensive research on coronaviruses in rodents enabled the discovery of new ones, the genome characteristics of which assigned them to alphacoronaviruses. One of these viruses was recently designated the Lucheng $\mathrm{Rn}$ species of rat coronavirus in a separate subgenus Luchacovirus. Such viruses are distributed worldwide, as recent studies revealed their presence also in Poland (105). The ranking of rodents as the largest order of mammals with more than 2000 species worldwide, their habitats sometimes in close proximity to other animals, and concomitantly the identification of rodent-associated CoVs belonging to different distinct subgenera gave cause for suspicion that these animals also may also play a significant role in the evolution and emergence of coronaviruses. Shrews, although less numerous in species (about 380 species worldwide) also seem important in this aspect.

Betacoronaviruses were also detected in a population of European hedgehogs (22). The newly discovered CoVs are include a unique species, Hedgehog coronavirus 1 (subgenus Merbecovirus), and it was not associated to any form of disease, so the hedgehog seems to be an asymptomatic reservoir of $\mathrm{CoV}$ which could contribute to the evolution of Merbecovirus (90).

\section{Summary}

Although coronaviruses are commonly found in farm, companion and wild animals, causing clinical and sometimes serious signs resulting in significant economic losses, not all of them have been classified by World Organization for Animal Health (OIE) as hazardous and included on the list of notifiable animal diseases. Historically, only two such diseases caused by coronaviruses were on the former list B of OIE diseases (TGE and IB). After the lists' unification, among 117 animal diseases there are currently three coronaviral entries (in addition to the two mentioned there is also 
PED). The occurrence of any of them or of one of the 114 other diseases on the OIE list of notifiable terrestrial and aquatic animal diseases should be registered in the World Animal Health Information System (WAHIS). However, none of these three coronaviral diseases entails any administrative measures (118). The emergence of the SARS-CoV-2 infection that caused the COVID-19 pandemic in humans and that most likely came from an animal reservoir has served to remind us of the critical importance of the One Health approach. The OIE has published recommendations on how to deal with suspected SARS-CoV-2 infections in animals. First of all, it requires close cooperation between veterinary and public health services and is aimed at limiting the spread of the disease and minimising the risk to human health. This document contains guiding principles for sampling and testing in suspected cases of SARS-COV-2 infection in animals. Any confirmed case should be notified as an emerging disease to the OIE through WAHIS (119). However, numerous SARS-CoV-2 infections found on mink farms in the Netherlands and on a few such farms in Denmark and Spain have forced veterinary services in those countries to take more radical steps. The relevant Dutch ministries have decided to cull and dispose of all mink on infected farms in order to avert the potential risks (78).

In conclusion, this review indicates the huge diversity of coronaviruses in the animal kingdom. Moreover, recent studies clearly showed that their occurrence and variability is highly underestimated. In vitro experiments have shown that multiple animal ACE2 homologous sequences (from a rhesus monkey, Mexican free-tailed bat, palm civet, raccoon dog, ferret badger, hog badger, dog, cat, rabbit, and pangolin) seem to be active as receptors for SARS-CoV-2 at different intensity levels, which could suggest roles variously as natural reservoirs or intermediate hosts of the virus (126). Therefore, domestic and wild animals should be intensively monitored to broaden our knowledge of viruses circulating among them, as well as to understand the mechanisms of the emergence of viruses of relevance to animal and human health.

Conflict of Interests Statement: The authors declare that there is no conflict of interests regarding the publication of this article.

Financial Disclosure Statement: Not applicable.

Animal Rights Statement: Not applicable.

\section{References}

1. Alexander L.K., Small J.D., Edwards S., Baric R.S.: An experimental model for dilated cardiomyopathy after rabbit coronavirus infection. J Infect Dis 1992, 166, 978-985.

2. Almeida J.D., Tyrrell D.A.: The morphology of three previously uncharacterized human respiratory viruses that grow in organ culture. J Gen Virol 1967, 1, 175-178.
3. Almendros A.: Can companion animals become infected with Covid-19? Vet Rec 2020, 186, 419-420.

4. Andersen K.G., Rambaut A., Lipkin W.I., Holmes E.C., Garry R.F.: The proximal origin of SARS-CoV-2. Nat Med 2020, 26, 450-452.

5. Ballesteros M.L., Sánchez C.M., Enjuanes L.: Two amino acid changes at the $\mathrm{N}$-terminus of transmissible gastroenteritis coronavirus spike protein result in the loss of enteric tropism. Virology 1997, 227, 378-388.

6. Bank T.W.: The World Livestock Disease Atlas. A quantitative analysis of global animal health data. 2011, Washington, USA: The World Bank.

7. Belsham G.J., Rasmussen T.B., Normann P., Vaclavek P., Strandbygaard B., Botner A.: Characterization of a novel chimeric swine enteric coronavirus from diseased pigs in Central Eastern Europe in 2016. Transbound Emerg Dis 2016, 63, 595-601.

8. Beltz L.A., Bats and coronaviruses. In: Bats and Human Health, John Wiley \& Sons, New York, 2018. pp. 111-138.

9. Bermingham A., Chand M.A., Brown C.S., Aarons E., Tong C., Langrish C., Hoschler K., Brown K., Galiano M., Myers R., Pebody R.G., Green H.K., Boddington N.L., Gopal R., Price N., Newsholme W., Drosten C., Fouchier R.A., Zambon M.: Severe respiratory illness caused by a novel coronavirus, in a patient transferred to the United Kingdom from the Middle East, September 2012. Euro Surv 2012, 17, 20290.

10. Bidokhti M.R.M., Tråvén M., Krishna N.K., Munir M., Belák S., Alenius S., Cortey M.: Evolutionary dynamics of bovine coronaviruses: natural selection pattern of the spike gene implies adaptive evolution of the strains. J Gen Virol 2013, 94, 2036-2049.

11. Boni M.F., Lemey P., Jiang X., Lam T.T.-Y., Perry B., Castoe T., Rambaut A., Robertson D.L.: Evolutionary origins of the SARSCoV-2 sarbecovirus lineage responsible for the COVID-19 pandemic. bioRxiv 2020, doi: 10/1101/2020.03.30.015008.

12. Borucki M.K., Allen J.E., Chen-Harris H., Zemla A., Vanier G., Mabery S., Torres C., Hullinger P., Slezak T.: The role of viral population diversity in adaptation of bovine coronavirus to new host environments. PLoS One 2013, 8, e52752.

13. Bouwman K.M., Delpont M., Broszeit F., Berger R., Weerts E.A.W.S., Lucas M.-N., Delverdier M., Belkasmi S., Papanikolaou A., Boons G.-J., Guérin J.-L., de Vries R.P., Ducatez M.F., Verheije M.H.: Guinea fowl coronavirus diversity has phenotypic consequences for glycan and tissue binding. J Virol 2019, 93, e00067-00019.

14. Brown P.A., Touzain F., Briand F.X., Gouilh A.M., Courtillon C., Allee C., Lemaitre E., De Boisseson C., Blanchard Y., Eterradossi N.: First complete genome sequence of European turkey coronavirus suggests complex recombination history related with US turkey and guinea fowl coronaviruses. J Gen Virol 2016, 97, 110-120.

15. Buonavoglia C., Decaro N., Martella V., Elia G., Campolo M., Desario C., Castagnaro M., Tempesta M.: Canine coronavirus highly pathogenic for dogs. Emerg Infect Dis 2006, 12, 492-494.

16. Cerioli M., Lavazza A.: 3.6. Viral enteritis of rabbits. In: Recent Advances in Rabbit Sciences, edited by L. Maertens and P. Coudert, Institute for Agricultural and Fisheries Research (ILVO), Animal Science Unit, Melle, 2006, pp 181-186.

17. Changhee L.: Porcine epidemic diarrhea virus: An emerging and re-emerging epizootic swine virus. Virol J 2015, 12, 193.

18. Cheever F.S., Daniels J.B., Pappenheimer A.M., Bailey O.T.: A murine virus (JHM) causing disseminated encephalomyelitis with extensive destruction of myelin. I. isolation and biological properties of the virus. J Exp Med 1949, 90, 181-194.

19. Chen Q., Gauger P.C., Stafne M.R., Thomas J.T., Madson D.M., Huang H., Zheng Y., Li G., Zhang J.: Pathogenesis comparison between the United States porcine epidemic diarrhoea virus prototype and S-INDEL-variant strains in conventional neonatal piglets. J Gen Virol 2016, 97, 1107-1121.

20. Chu D.K., Leung C.Y., Gilbert M., Joyner P.H., Ng E.M., Tse T.M., Guan Y., Peiris J.S., Poon L.L.: Avian coronavirus in wild aquatic birds. J Virol 2011, 85, 12815-12820. 
21. Cook J.K.A., Jackwood M., Jones R.C.: The long view: 40 years of infectious bronchitis research. Avian Path 2012, 41, 239-250.

22. Corman V.M., Kallies R., Philipps H., Göpner G., Müller M.A., Eckerle I., Brünink S., Drosten C., Drexler J.F.: Characterization of a novel betacoronavirus related to Middle East respiratory syndrome coronavirus in European hedgehogs. J Virol 2014, 88, 717-724, doi: 10.1128/JVI.01600-13.

23. Corman V.M., Muth D., Niemeyer D., Drosten C.: Chapter eight - hosts and sources of endemic human coronaviruses. In: Advances in Virus Research, edited by M. Kielian, T.C. Mettenleiter, and M.J. Roossinck, Academic Press, Waltham, pp. $163-188$

24. Cui J., Li F., Shi Z.-L.: Origin and evolution of pathogenic coronaviruses. Nat Rev Microbiol 2019, 17, 181-192.

25. de Groot R.J., Horzinek M.J.: Feline infectious peritonitis. In: The Coronaviridae, edited by S.C. Siddell, Plenum, New York, 1995, pp. 293-309.

26. de Groot R.J., Ziebuhr J., Poon L.L., Woo P.C., Talbot P., Rottier P.J.M.: Revision of the family Coronaviridae. Taxonomic proposal of the Coronavirus Study Group to the ICTV Executive Committee. 2008. http://talk.ictvonline.org/media/p/1230.aspx.

27. de Wit J.J., Cook J.K.A., van der Heijden H.M.J.F.: Infectious bronchitis virus variants: a review of the history, current situation and control measures. Avian Path 2011, 40, 223-235.

28. Decaro N., Lorusso A.: Novel human coronavirus (SARS-CoV-2): A lesson from animal coronaviruses. Vet Microbiol 2020, 244, 108693.

29. Drexler J.F., Corman V.M., Drosten C.: Ecology, evolution and classification of bat coronaviruses in the aftermath of SARS. Antiviral Res 2014, 101, 45-56.

30. Ellis J.: What is the evidence that bovine coronavirus is a biologically significant respiratory pathogen in cattle? Can Vet J 2019, 60, 147-152.

31. Ellis J.A., McLean N., Hupaelo R., Haines D.M.: Detection of coronavirus in cases of tracheobronchitis in dogs: a retrospective study from 1971 to 2003. Can Vet J 2005, 46, 447-448.

32. Erles K., Brownlie J.: Investigation into the causes of canine infectious respiratory disease: antibody responses to canine respiratory coronavirus and canine herpesvirus in two kennelled dog populations. Arch Virol 2005, 150, 1493-1504.

33. Erles K., Shiu K.B., Brownlie J.: Isolation and sequence analysis of canine respiratory coronavirus. Virus Res 2007, 124, 78-87.

34. Erles K., Toomey C., Brooks H.W., Brownlie J.: Detection of a group 2 coronavirus in dogs with canine infectious respiratory disease. Virology 2003, 310, 216-223.

35. Fehr A.R., Perlman S.: Coronaviruses: an overview of their replication and pathogenesis. Methods Mol Biol 2015, 1282, $1-23$.

36. Foley J.E., Poland A., Carlson J., Pedersen N.C.: Patterns of feline coronavirus infection and fecal shedding from cats in multiple-cat environments. J Am Vet Med Ass 1997, 210, 1307-1312.

37. Forni D., Cagliani R., Clerici M., Sironi M.: Molecular evolution of human coronavirus genomes. Trends Microbiol 2017, 25, 35-48.

38. Ge X.-Y., Li J.-L., Yang X.-L., Chmura A.A., Zhu G., Epstein J.H., Mazet J.K., Hu B., Zhang W., Peng C., Zhang Y.-J., Luo C.-M., Tan B., Wang N., Zhu Y., Crameri G., Zhang S.-Y., Wang L.-F., Daszak P., Shi Z.-L.: Isolation and characterization of a bat SARS-like coronavirus that uses the ACE2 receptor. Nature 2013, 503, 535-538.

39. Gélinas A.M., Sasseville A.J., Dea S.: Identification of specific variations within the HE, S1, and ORF4 genes of bovine coronaviruses associated with enteric and respiratory diseases in dairy cattle. In: The Nidoviruses, edited by S. Perlman, K.V. Holmes, Springer, Boston, 2001, pp. 63-67.

40. Halfmann P.J., Hatta M., Chiba S., Maemura T., Fan S., Takeda M., Kinoshita N., Hattori S., Sakai-Tagawa Y., Iwatsuki-Horimoto K., Imai M., Kawaoka Y.: Transmission of SARS-CoV-2 in domestic cats. New Eng J Med 2020, doi: 10.1056/NEJMc2013400.
41. Hepojoki S., Lindh E., Vapalahti O., Huovilainen A.: Prevalence and genetic diversity of coronaviruses in wild birds, Finland. Infect Ecol Epidemiol 2017, 7, 1408360, doi: 10.1080/20008686. 2017.1408360

42. Herrewegh A.A., Vennema H., Horzinek M.C., Rottier P.J., de Groot R.J.: The molecular genetics of feline coronaviruses: comparative sequence analysis of the $\mathrm{ORF} 7 \mathrm{a} / 7 \mathrm{~b}$ transcription unit of different biotypes. Virology 1995, 212, 622-631.

43. Hoffmann M., Kleine-Weber H., Schroeder S., Krüger N., Herrler T., Erichsen S., Schiergens T.S., Herrler G., Wu N.-H., Nitsche A., Müller M.A., Drosten C., Pöhlmann S.: SARS-CoV-2 cell entry depends on ACE2 and TMPRSS2 and is blocked by a clinically proven protease inhibitor. Cell 2020, 181, 271-280, e278, doi: 10.1016/j.cell.2020.02.052.

44. Hohdatsu T., Nakamura M., Ishizuka Y., Yamada H., Koyama H.: A study on the mechanism of antibody-dependent enhancement of feline infectious peritonitis virus infection in feline macrophages by monoclonal antibodies. Arch Virol 1991, 120, 207-217.

45. Hohdatsu T., Okada S., Koyama H.: Characterization of monoclonal antibodies against feline infectious peritonitis virus type II and antigenic relationship between feline, porcine, and canine coronaviruses. Arch Virol 1991, 117, 85-95.

46. Jackwood M.W., Boynton T.O., Hilt D.A., McKinley E.T., Kissinger J.C., Paterson A.H., Robertson J., Lemke C., McCall A.W., Williams S.M., Jackwood J.W., Byrd L.A.: Emergence of a group 3 coronavirus through recombination. Virology 2010, 398, 98-108.

47. Jackwood M.W., de Wit S.: Infectious bronchitis. In: Diseases of Poultry, edited by D.E. Swayne, Wiley-Blackwell. Hoboken, 2013, pp. 139-160

48. Jackwood M.W., Hall D., Handel A.: Molecular evolution and emergence of avian gammacoronaviruses. Infect Gen Evol 2012, 12, 1305-1311.

49. Jung K., Annamalai T., Lu Z., Saif L.J.: Comparative pathogenesis of US porcine epidemic diarrhea virus (PEDV) strain PC21A in conventional 9-day-old nursing piglets vs. 26day-old weaned pigs. Vet Microbiol 2015, 178, 31-40.

50. Keha A., Xue L., Yan S., Yue H., Tang C.: Prevalence of a novel bovine coronavirus strain with a recombinant hemagglutinin/ esterase gene in dairy calves in China. Transbound Emerg Dis 2019, 66, 1971-1981.

51. Kin N., Miszczak F., Diancourt L., Caro V., Moutou F., Vabret A., Ar Gouilh M.: Comparative molecular epidemiology of two closely related coronaviruses, bovine coronavirus (BCoV) and human coronavirus OC43 (HCoV-OC43), reveals a different evolutionary pattern. Infect Genet Evol 2016, 40, 186-191, doi: 10.1016/j.meegid.2016.03.006.

52. Laconi A., Listorti V., Franzo G., Cecchinato M., Naylor C., Lupini C., Catelli E.: Molecular characterization of whole genome sequence of infectious bronchitis virus 624I genotype confirms the close relationship with Q1 genotype. Transbound Emerg Dis 2019, 66, 207-216

53. Latinne A., Hu B., Olival K.J., Zhu G., Zhang L., Li H., Chmura A.A., Field H.E., Zambrana-Torrelio C., Epstein J.H., Li B., Zhang W., Wang L.-F., Shi Z.-L., Daszak P.: Origin and crossspecies transmission of bat coronaviruses in China. bioRxiv 2020, doi: 10/1101/2020.05.31.116061.

54. Lau S.K., Woo P.C., Li K.S., Tsang A.K., Fan R.Y., Luk H.K., Cai J.P., Chan K.H., Zheng B.J., Wang M., Yuen K.Y.: Discovery of a novel coronavirus, China Rattus coronavirus HKU24, from Norway rats supports the murine origin of Betacoronavirus 1 and has implications for the ancestor of Betacoronavirus lineage A. J Virol 2015, 89, 3076-3092.

55. Lau S.K.P., Woo P.C.Y., Yip C.C.Y., Fan R.Y.Y., Huang Y., Wang M., Guo R., Lam C.S.F., Tsang A.K.L., Lai K.K.Y., Chan K.-H., Che X.-Y., Zheng B.-J., Yuen K.-Y.: Isolation and characterization of a novel Betacoronavirus subgroup A coronavirus, rabbit coronavirus HKU14, from domestic rabbits. J Virol 2012, 86, 5481-5496.

56. Laude H., Van Reeth K., Pensaert M.: Porcine respiratory coronavirus: molecular features and virus-host interactions. Vet Res 1993, 24, 125-150. 
57. Le Poder S.: Feline and canine coronaviruses: common genetic and pathobiological features. Adv Virol 2011, 2011, 609465, doi: $10.1155 / 2011 / 609465$.

58. Letko M., Marzi A., Munster V.: Functional assessment of cell entry and receptor usage for SARS-CoV-2 and other lineage B betacoronaviruses. Nat Microbiol 2020, 5, 562-569.

59. Li F.: Evidence for a common evolutionary origin of coronavirus spike protein receptor-binding subunits. J Virol 2012, 86, 2856-2858.

60. Li F.: Structure, function, and evolution of coronavirus spike proteins. Ann Rev Virol 2016, 3, 237-261.

61. Li R., Qiao S., Zhang G.: Analysis of angiotensin-converting enzyme 2 (ACE2) from different species sheds some light on cross-species receptor usage of a novel coronavirus 2019-nCoV. J Infect 2020, 80, 469-496.

62. Li Z., He W., Lan Y., Zhao K., Lv X., Lu H., Ding N., Zhang J., Shi J., Shan C., Gao F.: The evidence of porcine hemagglutinating encephalomyelitis virus induced nonsuppurative encephalitis as the cause of death in piglets. Peer J 2016, 4, e2443-e2443.

63. Liais E., Croville G., Mariette J., Delverdier M., Lucas M.N., Klopp C., Lluch J., Donnadieu C., Guy J.S., Corrand L., Ducatez M.F., Guerin J.L.: Novel avian coronavirus and fulminating disease in guinea fowl, France. Emerg Infect Dis 2014, 20, 105-108.

64. Lu S., Chen Y., Qin K., Zhou J., Lou Y., Tan W.: Genetic and antigenic characterization of recombinant nucleocapsid proteins derived from canine coronavirus and canine respiratory coronavirus in China. Sci China Life Sci 2016, 59, 615-621.

65. Lv C., Xiao Y., Li X., Tian K.: Porcine epidemic diarrhea virus: current insights. Vir Adapt Treat 2016, 8, 1-12.

66. Ma G., Feng Y., Gao F., Wang J., Liu C., Li Y.: Biochemical and biophysical characterization of the transmissible gastroenteritis coronavirus fusion core. Biochem Biophys Res Commun 2005, 337, 1301-1307.

67. MacLean O.A., Lytras S., Singer J.B., Weaver S., Pond S.L.K., Robertson D.L.: Evidence of significant natural selection in the evolution of SARS-CoV-2 in bats, not humans. bioRxiv 2020, doi: 10/1101/2020.05.28.122366.

68. Mandelik R., Sarvas M., Jackova A., Salamunova S., Novotny J., Vilcek S.: First outbreak with chimeric swine enteric coronavirus $(\mathrm{SeCoV})$ on pig farms in Slovakia - lessons to learn. Acta Vet Hun 2018, 66, 488-492.

69. Marandino A., Tomás G., Panzera Y., Greif G., Parodi-Talice A., Hernández M., Techera C., Hernández D., Pérez R.: Wholegenome characterization of Uruguayan strains of avian infectious bronchitis virus reveals extensive recombination between the two major South American lineages. Infect Gen Evol 2017, 54, 245-250.

70. Martelli P., Lavazza A., Nigrelli A.D., Merialdi G., Alborali L.G., Pensaert M.B.: Epidemic of diarrhoea caused by porcine epidemic diarrhoea virus in Italy. Vet Rec 2008, 162, 307-310.

71. Martina B.E.E., Haagmans B.L., Kuiken T., Fouchier R.A.M., Rimmelzwaan G.F., Van Amerongen G., Peiris J.S.M., Lim W., Osterhaus A.D.M.E.: Virology: SARS virus infection of cats and ferrets. Nature 2003, 425, 915-915.

72. Masters P.S., Perlman S.: Coronaviridae. In: Fields virology, edited by D.M. Knipe and P.M. Howley, Lippincot Williams \& Wilkins, Philadelphia, 2013, pp. 825-858.

73. Mohd H.A., Al-Tawfiq J.A., Memish Z.A.: Middle East Respiratory Syndrome Coronavirus (MERS-CoV) origin and animal reservoir. Virol J 2016, 13, 87, doi: 10.1186/s12985-0160544-0.

74. Monchatre-Leroy E., Boué F., Boucher J.M., Renault C., Moutou F., Ar Gouilh M., Umhang G.: Identification of alpha and beta coronavirus in wildlife species in France: bats, rodents, rabbits, and hedgehogs. Viruses 2017, 9, 364

75. Morales R.G., Umandal A.C., Lantican C.A.: Emerging and reemerging diseases in Asia and the Pacific with special emphasis on porcine epidemic diarrhoea. In: 25th Conference of the OIE Regional Commission for Asia, the Far East and Oceania Queenstown, (New Zealand), 27-30 November 2007, pp. 185-189.
76. Motokawa K., Hohdatsu T., Hashimoto H., Koyama H.: Comparison of the amino acid sequence and phylogenetic analysis of the peplomer, integral membrane and nucleocapsid proteins of feline, canine and porcine coronaviruses. Microbiol Imm 1996, 40, 425-433.

77. Muradrasoli S., Balint A., Wahlgren J., Waldenstrom J., Belak S., Blomberg J., Olsen B.: Prevalence and phylogeny of coronaviruses in wild birds from the Bering Strait area (Beringia). PLoS One 2010, 5, e13640.

78. Netherlands (Government of the): Government adopts advice to cull mink on infected farms. 3 June 2020. https://www.government.nl/latest/news/2020/06/09/governmentadopts-advice-to-cull-mink-on-infected-farms.

79. Opressnig T.: Porcine epidemic diarrhea (PED) in Europe and strategies to control outbreaks. Jap J Vet Res. 2016, 64, 35-38.

80. Pedersen N.C.: Virologic and immunologic aspects of feline infectious peritonitis virus infection. Adv Exp Med Biol 1987, 218, 529-550.

81. Pensaert M.: Transmissible gastroenteritis virus (respiratory variant). In: Virus infections of porcines, edited by M. Pensaert, Elsevier Science Publishers, Amsterdam, 1989.

82. Pensaert M., Callebaut P., Vergote J.: Isolation of a porcine respiratory, non-enteric coronavirus related to transmissible gastroenteritis. Vet Quart 1986, 8, 257-261.

83. Pratelli A., Martella V., Decaro N., Tinelli A., Camero M., Cirone F., Elia G., Cavalli A., Corrente M., Greco G., Buonavoglia D., Gentile M., Tempesta M., Buonavoglia C.: Genetic diversity of a canine coronavirus detected in pups with diarrhoea in Italy. J Virol Methods 2003, 110, 9-17.

84. Priestnall S.L., Brownlie J., Dubovi E.J., Erles K.: Serological prevalence of canine respiratory coronavirus. Vet Microbiol 2006, $115,43-53$.

85. Priestnall S.L., Pratelli A., Brownlie J., Erles K.: Serological prevalence of canine respiratory coronavirus in southern Italy and epidemiological relationship with canine enteric coronavirus. J Vet Diag Inv 2007, 19, 176-180.

86. Pusterla N., Vin R., Leutenegger C., Mittel L.D., Divers T.J.: Equine coronavirus: An emerging enteric virus of adult horses. Equine Vet Educ 2016, 28, 216-223.

87. Rasmussen T.B., Boniotti M.B., Papetti A., Grasland B., Frossard J.-P., Dastjerdi A., Hulst M., Hanke D., Pohlmann A., Blome S., van der Poel W.H.M., Steinbach F., Blanchard Y., Lavazza A., Bøtner A., Belsham G.J.: Full-length genome sequences of porcine epidemic diarrhoea virus strain CV777; Use of NGS to analyse genomic and sub-genomic RNAs. PLoS One 2018, 13, e0193682, doi: 10.1371/journal.pone.0193682.

88. Saif L.J., Jung K.: Comparative pathogenesis of bovine and porcine respiratory coronaviruses in the animal host species and SARS-CoV-2 in humans. J Clin Microbiol 2020, JCM.01355-20. doi: 10.1128/JCM.01355-20.

89. Saif L.J., Pensaert M.B., Sestak K., Yeo S.-G., Jung K.: Coronaviruses. In: Diseases of swine, edited by J.J. Zimmerman, L.A. Karriker, A. Ramirez, K.J. Schwartz, G.W. Stevenson, J. Zhang, Wiley-Blackwell, Ames, 2012, pp. 501-524.

90. Saldanha I.F., Lawson B., Goharriz H., Rodriguez-Ramos Fernandez J., John S.K., Fooks A.R., Cunningham A.A., Johnson N., Horton D.L.: Extension of the known distribution of a novel clade $\mathrm{C}$ betacoronavirus in a wildlife host. Epidemiol Infect 2019, 147, e169.

91. Salem E., Dhanasekaran V., Cassard H., Hause B., Maman S., Meyer G., Ducatez M.F.: Global transmission, spatial segregation, and recombination determine the long-term evolution and epidemiology of bovine coronaviruses. Viruses 2020, 12, 534, doi: $10.3390 / \mathrm{v} 12050534$

92. Sanchez C.M., Izeta A., Sanchez-Morgado J.M., Alonso S., Sola I., Balasch M., Plana-Duran J., Enjuanes L.: Targeted recombination demonstrates that the spike gene of transmissible gastroenteritis coronavirus is a determinant of its enteric tropism and virulence. J Virol 1999, 73, 7607-7618.

93. Schalk A.F.: An apparent new respiratory disease of baby chicks. J Am Vet Med Assoc 1931, 78, 413-422. 
94. Shi J., Wen Z., Zhong G., Yang H., Wang C., Huang B., Liu R., He X., Shuai L., Sun Z., Zhao Y., Liu P., Liang L., Cui P., Wang J., Zhang X., Guan Y., Tan W., Wu G., Chen H., Bu Z.: Susceptibility of ferrets, cats, dogs, and other domesticated animals to SARS-coronavirus 2. Science 2020, 368, 1016-1020, doi: 10.1126/science. abb7015.

95. Siddell S.G., Anderson R., Cavanagh D., Fujiwara K., Klenk H.D., Macnaughton M.R., Pensaert M., Stohlman S.A., Sturman L., van der Zeijst B.A.: Coronaviridae. Intervirology 1983, 20, 181-189.

96. Song J.H., Shim J.K., Choi H.J.: Quercetin 7-rhamnoside reduces porcine epidemic diarrhea virus replication via independent pathway of viral induced reactive oxygen species. Virol J 2011,8, 460, doi: 10.1186/1743-422X-8-460.

97. Steinbach F., Dastjerdi A., Peake J., La Rocca S.A., Tobin F.P., Frossard J.-P., Williamson S.: A retrospective study detects a novel variant of porcine epidemic diarrhea virus in England in archived material from the year 2000. PeerJ 2016, 4, e2564, doi: 10.7717/peerj.2564.

98. Su S., Wong G., Shi W., Liu J., Lai A.C.K., Zhou J., Liu W., Bi Y., Gao G.F.: Epidemiology, genetic recombination, and pathogenesis of coronaviruses. Trends Microbiol 2016, 24, 490-502.

99. Suzuki T., Otake Y., Uchimoto S., Hasebe A., Goto Y.: Genomic characterization and phylogenetic classification of bovine coronaviruses through whole genome sequence analysis. Viruses 2020, 12, 183, doi: 10.3390/v12020183.

100.Tang X., Wu C., Li X., Song Y., Yao X., Wu X., Duan Y., Zhang H., Wang Y., Qian Z., Cui J., Lu J.: On the origin and continuing evolution of SARS-CoV-2. Nat Sci Rev 2020, 7, 1012-1023.

101.Temmam S., Barbarino A., Maso D., Behillil S., Enouf V., Huon C., Jaraud A., Chevallier L., Backovic M., Pérot P., Verwaerde P., Tiret L., van der Werf S., Eloit M.: Absence of SARS-CoV-2 infection in cats and dogs in close contact with a cluster of COVID-19 patients in a veterinary campus. bioRxiv 2020, doi: 10/1101/2020.04.07.029090.

102.Tennant B.J., Gaskell R.M., Kelly D.F., Carter S.D., Gaskell C.J.: Canine coronavirus infection in the $\operatorname{dog}$ following oronasal inoculation. Res Vet Sci 1991, 51, 11-18.

103.Tilocca B., Soggiu A., Musella V., Britti D., Sanguinetti M., Urbani A., Roncada P.: Molecular basis of COVID-19 relationships in different species: a one health perspective. Microbes Infect 2020, 22, 218-220.

104.Tilocca B., Soggiu A., Sanguinetti M., Musella V., Britti D., Bonizzi L., Urbani A., Roncada P.: Comparative computational analysis of SARS-CoV-2 nucleocapsid protein epitopes in taxonomically related coronaviruses. Microbes Infect 2020, 22, 188-194.

105.Tsoleridis T., Onianwa O., Horncastle E., Dayman E., Zhu M., Danjittrong T., Wachtl M., Behnke J.M., Chapman S., Strong V., Dobbs P., Ball J.K., Tarlinton R.E., McClure C.P.: Discovery of novel alphacoronaviruses in european rodents and shrews. Viruses 2016, 8, 84, doi: 10.3390/v8030084.

106.United States Department of Agriculture Animal and Plant Health Inspection Service: USDA Statement on the confirmation of COVID-19 in a tiger in New York. April 6, 2020. https://www.aphis.usda.gov/aphis/newsroom/news/sa_by_date/sa -2020/ny-zoo-covid-19.

107.Valastro V., Holmes E.C., Britton P., Fusaro A., Jackwood M.W., Cattoli G., Monne I.: S1 gene-based phylogeny of infectious bronchitis virus: An attempt to harmonize virus classification. Infect Genet Evol 2016, 39, 349-364.

108.Vennema H., Poland A., Foley J., Pedersen N.C.: Feline infectious peritonitis viruses arise by mutation from endemic feline enteric coronaviruses. Virology 1998, 243, 150-157.

109.Vijgen L., Keyaerts E., Moës E., Thoelen I., Wollants E., Lemey P., Vandamme A.M., Van Ranst M.: Complete genomic sequence of human coronavirus OC43: molecular clock analysis suggests a relatively recent zoonotic coronavirus transmission event. J Virol 2005, 79, 1595-1604.
110.Vlasova A.N., Wang Q., Jung K., Langel S.N., Malik Y.S., Saif L.J.: Porcine coronaviruses. Emerg Trans Animal Virol 2020, 79-110.

111.Wang L.F., Eaton B.T.: Bats, civets and the emergence of SARS. Curr Top Microbiol Immunol 2007, 315, 325-344.

112.Wang Q., Vlasova A.N., Kenney S.P., Saif L.J.: Emerging and re-emerging coronaviruses in pigs. Curr Opinion Virol 2019, 34, $39-49$.

113.Wang W., Lin X.D., Guo W.P., Zhou R.H., Wang M.R., Wang C.Q., Ge S., Mei S.H., Li M.H., Shi M., Holmes E.C., Zhang Y.Z.: Discovery, diversity and evolution of novel coronaviruses sampled from rodents in China. Virology 2015 , 474, 19-27.

114.Wickramasinghe I.N.A., de Vries R.P., Weerts E.A.W.S., van Beurden S.J., Peng W., McBride R., Ducatez M., Guy J., Brown P., Eterradossi N., Grone A., Paulson J.C., Verheijea M.H.: Novel receptor specificity of avian gammacoronaviruses that cause enteritis. J Virol 2015, 89, 8783-8792.

115.Wille M., Harvey E., Shi M., Gonzalez-Acuna D., Holmes E.C., Hurt A.C.: Sustained RNA virome diversity in Antarctic penguins and their ticks. Isme J 2020, 14, 1768-1782.

116.Wille M., Muradrasoli S., Nilsson A., Jarhult J.D.: High prevalence and putative lineage maintenance of avian coronaviruses in Scandinavian waterfowl. PLoS One 2016, 11, e150198, doi: 10.1371/journal.pone.0150198.

117.Woo P.C., Lau S.K., Huang Y., Yuen K.Y.: Coronavirus diversity, phylogeny and interspecies jumping. Exp Biol Med (Maywood) 2009, 234, 1117-1127.

118. World Organisation for Animal Health (OIE): Terrestrial Animal Health Code $28^{\text {th }}$ Edition, Paris, 2019. http://www.oie.int/ en/international-standard-setting/terrestrial-code/access-online/.

119. World Organisation for Animal Health (OIE): Considerations for sampling, testing, and reporting of SARS-CoV-2 in animals, Paris, 2020. http://www.oie.int/fileadmin/Home/eng/Our scientific expertise/docs/pdf/COV-19/Sampling Testing and Reporting_of_SARS-CoV-2_in_animals_final_7May_2020.pdf.

120.Yachi A., Mochizuki M.: Survey of dogs in Japan for group 2 canine coronavirus infection. J Clin Microbiol 2006, 44, 2615-2618.

121.Zeng Q., Langereis M.A., van Vliet A.L.W., Huizinga E.G., de Groot R.J.: Structure of coronavirus hemagglutinin-esterase offers insight into corona and influenza virus evolution. Proc Natl Acad Sci USA 2008, 105, 9065-9069.

122.Zhang J., Guy J.S., Snijder E.J., Denniston D.A., Timoney P.J., Balasuriya U.B.: Genomic characterization of equine coronavirus. Virology 2007, 369, 92-104.

123.Zhang J.Q.: Porcine deltacoronavirus: Overview of infection dynamics, diagnostic methods, prevalence and genetic evolution. Virus Res 2016, 226, 71-84.

124.Zhang Q., Zhang H., Huang K., Yang Y., Hui X., Gao J., He X., Li C., Gong W., Zhang Y., Peng C., Gao X., Chen H., Zou Z., Shi Z., Jin M.: SARS-CoV-2 neutralizing serum antibodies in cats: a serological investigation. bioRxiv 2020, doi: 10/1101/2020.04. 01.021196

125.Zhang X.M., Herbst W., Kousoulas K.G., Storz J.: Biological and genetic characterization of a hemagglutinating coronavirus isolated from a diarrhoeic child. J Med Virol 1994, 44, 152-161.

126.Zhao J., Chen D., Szabla R., Zheng M., Li G., Du P., Zheng S., Li X., Song C., Li R., Guo J.-T., Junop M., Zeng H., Lin H.: Broad and differential animal ACE2 receptor usage by SARS-CoV-2. bioRxiv 2020, doi: 10/1101/2020.04.19.048710.

127.Zhou L., Li Q.N., Su J.N., Chen G.H., Wu Z.X., Luo Y., Wu R.T., Sun Y., Lan T., Ma J.Y.: The re-emerging of SADS-CoV infection in pig herds in Southern China. Transbound Emerg Dis 2019, 66, 2180-2183.

128.Zhou P., Fan H., Lan T., Yang X.-L., Shi W.-F., Zhang W., Zhu Y., Zhang Y.-W., Xie Q.-M., Mani S., Zheng X.-S., Li B., Li J.-M., Guo H., Pei G.-Q., An X.-P., Chen J.-W., Zhou L., Mai K.-J., Wu Z.-X., Li D., Anderson D.E., Zhang L.-B., Li S.-Y., Mi Z.-Q., He T.-T., Cong F., Guo P.-J., Huang R., Luo Y., Liu X.-L., Chen J., Huang Y., Sun Q., Zhang X.-L.-L., 
Wang Y.-Y., Xing S.-Z., Chen Y.-S., Sun Y., Li J., Daszak P., Wang L.-F., Shi Z.-L., Tong Y.-G., Ma J.-Y.: Fatal swine acute diarrhoea syndrome caused by an HKU2-related coronavirus of bat origin. Nature 2018, 556, 255-258.

129.Zhou P., Yang X.-L., Wang X.-G., Hu B., Zhang L., Zhang W., Si H.-R., Zhu Y., Li B., Huang C.-L., Chen H.-D., Chen J., Luo Y., Guo H., Jiang R.-D., Liu M.-Q., Chen Y., Shen X.-R., Wang X., Zheng X.-S., Zhao K., Chen Q.-J., Deng F., Liu L.-L.,
Yan B., Zhan F.-X., Wang Y.-Y., Xiao G.-F., Shi Z.-L.: A pneumonia outbreak associated with a new coronavirus of probable bat origin. Nature 2020, 579, 270-273.

130.Zhuang Q.Y., Wang K.C., Liu S., Hou G.Y., Jiang W.M., Wang S.C., Li J.P., Yu J.M., Chen J.M.: Genomic analysis and surveillance of the coronavirus dominant in ducks in China. PLoS One 2015, 10, e0129256, doi: 10.1371/journal.pone.0129256. 